Research Article

\title{
Study on Long-Term Performance of Geogrid-Reinforced and Pile-Supported Embankment at Bridge Approach
}

\author{
Jun Zhang $\mathbb{D}^{1,2}$ Ziyang Zhao $\mathbb{D}^{2}{ }^{2}$ and Zhijie Sun $\mathbb{D D}^{2}$ \\ ${ }^{1}$ College of Transportation Engineering, Tongji University, Shanghai 201804, China \\ ${ }^{2}$ Key Laboratory of Highway Construction and Maintenance Technology in Loess Region, \\ Shanxi Transportation Technology Research \& Development Co., Ltd., Taiyuan 030032, China \\ Correspondence should be addressed to Jun Zhang; zj_sxjt@hotmail.com
}

Received 26 February 2021; Revised 23 March 2021; Accepted 31 March 2021; Published 13 April 2021

Academic Editor: Haohui Xin

Copyright (C) 2021 Jun Zhang et al. This is an open access article distributed under the Creative Commons Attribution License, which permits unrestricted use, distribution, and reproduction in any medium, provided the original work is properly cited.

\begin{abstract}
Bridges have been widely used in highway and railway engineering, especially in mountain areas. The differential settlement between bridge abutment and approach embankment is one of the most challenging problems, and it will result in "bumps" to affect the driving safety and comfortableness at the end of a bridge. The geogrid-reinforced and pile-supported embankment (GRPS embankment) is proposed to mitigate the differential settlement at the bridge approach. In this paper, the model tests and numerical studies are carried out to study the long-term performance of the GRPS embankment considering the consolidation of subsoil. Firstly, a series of model tests are conducted to evaluate the long-term performance of the GRPS embankment using a specially designed model box. Then, the numerical model is constructed using the finite element software MIDAS, and the numerical model is verified from the model test results. Finally, a parametric study is conducted to investigate the influences of pile net spacing, pile modulus, and filling modulus.
\end{abstract}

\section{Introduction}

Bump at bridge head is commonly encountered at roadbridge transition section, which is caused by the differential settlement between bridge abutment and approach embankment [1-3]. This bridge bump will in turn intensify the differential settlement between bridge abutment and approach embankment and affect the safety and comfort of driving. To mitigate the differential settlement, several ground treatment approaches or subgrade structures have been applied for the construction of the road-bridge transition section, such as the geogrid-reinforced and pilesupported embankment (GRPS embankment) [4-6].

GRPS embankment is a type of earth structure that combines the effects of both pile and reinforcement as the bearing system for embankments, as shown in Figure 1. This type of embankments has the advantages of small settlement, short construction period, and convenient construction [7-9]. In terms of theoretical research, as early as 1936, Terzaghi proved the existence of the soil arch effect based on the movable door test of sand. At the same time, the trenchtype soil arch model of the ideal soil is proposed by assuming the vertical shear plane between the internal and external soil columns [10]. Based on this vertical shear plane assumption, the mechanical models of the GRPS embankment are established [11-13]. The settlement, strain of geogrid, and pile efficiency in the GRPS embankment under different conditions are analyzed [14-16]. The two-dimensional and three-dimensional discrete element numerical models are established to analyze the loads transferred through the soilarching effect, tensioned-membrane effect, and subsoil under embankment load $[17,18]$.

In summary, the related research almost has not yet involved the long-term effect of soil consolidation, and it cannot truly reflect the actual working behavior of the GRPS embankment. In this study, the model tests and numerical studies are carried out to study the long-term performance of the GRPS embankment considering the consolidation of subsoil. The parametric study is conducted to evaluate the effects of pile net spacing, pile modulus, and filling modulus. 


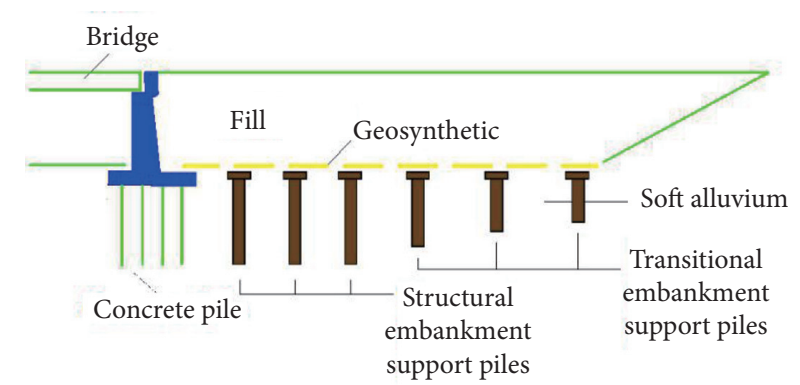

FIGURE 1: Sketch of the GRPS embankment used at bridge approach.

\section{Model Test}

2.1. Testing Equipment. An indoor model test system is specially designed, as shown in Figure 2; the system is mainly composed of tempered glass test tank, pile, lifting system, and high-speed camera device. The length, width, and height of the tempered glass test tank are $2 \mathrm{~m}, 1 \mathrm{~m}$, and $1 \mathrm{~m}$, respectively. The pile height in the tempered glass test tank and filling height above the pile are both $50 \mathrm{~cm}$. The lifting system is $25 \mathrm{~cm}$ away from the bottom of the tempered glass test tank. The diameter of middle three piles is $25 \mathrm{~cm}$, and the diameter of two piles at the side is $12.5 \mathrm{~cm}$. The lifting system is closely connected with two movable loading plates, through two holes opened at the bottom of the test tank, which is used to simulate the consolidation settlement of subsoil. The elevation of the lifting system decreases by $0.5 \mathrm{~mm}$ after each turn of counterclockwise rotation. The high-speed camera is installed directly in front of the tempered glass test tank. During the model test carried out, the focal length is fixed and photos are taken continuously. Then, the settlement of filling is obtained through PIV analysis.

2.2. Test Series. The model tests of the GRPS embankment are carried out using the abovementioned model test system. The reinforced and unreinforced pile-supported embankments are investigated. The specific test series are shown in Table 1.

\subsection{Experimental Material. Pingtan standard sand is se-} lected for the embankment filling and sand between piles in the test. The density, Poisson ratio, and internal frictional angle of Pingtan standard sand are $1620 \mathrm{~kg} / \mathrm{m}^{3}, 0.3$, and $27^{\circ}$, respectively. The geogrid is selected as the triaxial geogrid made of high-density polyethylene (HDPE) commonly used in engineering applications. The related physical indexes are detailed in Table 2. The pile is a hollow rectangular box made of steel plates with the thickness of $0.5 \mathrm{~cm}$. The height and length of pile is $50 \mathrm{~cm} 100 \mathrm{~cm}$, respectively.

The universal material testing machine is used to carry out single-rib tensile test of the geogrid, and the results are shown in Figure 3. The slope of secant line and ultimate failure strength are, respectively, taken as the tensile stiffness and strength.

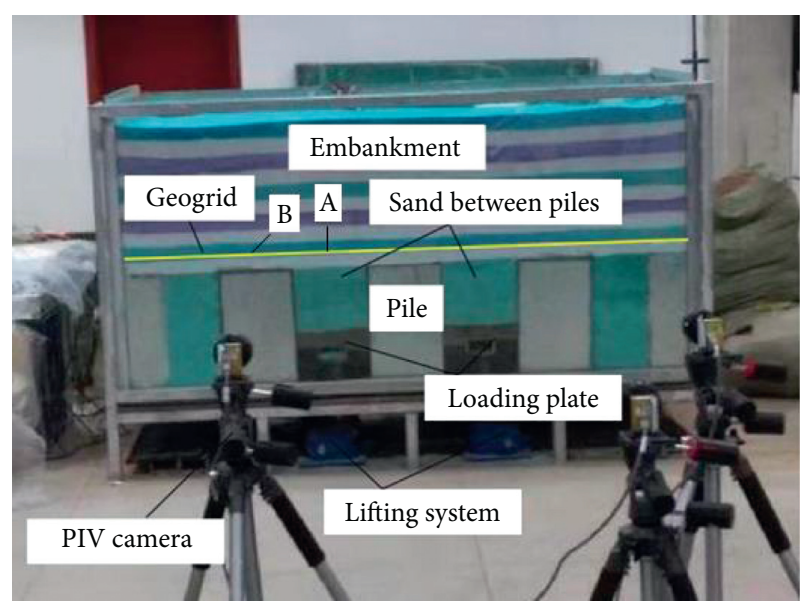

Figure 2: Model test system.

2.4. Testing Procedures. The specific test steps are as follows:

(a) A part of standard sand is stained with a kind of biological dye.

(b) Two piles with the diameter of $12.5 \mathrm{~cm}$ are arranged on the left and right sides of the tempered glass test tank. The middle three piles with the diameter of $25 \mathrm{~cm}$ are arranged according to the pile net spacing of $25 \mathrm{~cm}$.

(c) The high-speed camera in front of the test tank is activated to take continuous pictures of the embankment filling process.

(d) Each layer is alternately filled with dyed and undyed sand filling and tamped to a predetermined height with a tamping plate. The thickness of each sand layer is $50 \mathrm{~mm}$, and a total of ten layers are laid. Under the one-layer geogrid-reinforced condition, the geogrid is laid at the filling height of $5 \mathrm{~cm}$. However, under the two-layer geogrids' condition, the first layer geogrid is laid at the filling height of $5 \mathrm{~cm}$, and the second layer geogrid is laid at the filling height of $25 \mathrm{~cm}$. Especially, the edge of the geogrid is fixed with the reserved holes' sleeve rings on the left and right piles, which restricts the horizontal displacement but allows the vertical displacement of the geogrid.

(e) After the completion of embankment filling, it is allowed to stand for 24 hours. The lifting system rotates once every half an hour for a total of 10 times and 10 turns for every time. When the descending height of the lifting system reaches to $50 \mathrm{~mm}$, the test is finished.

(f) The settlement of filling is obtained through PIV analysis.

2.5. Results. In the pile diameter of $25 \mathrm{~cm}$ and one-layer geogrid-reinforced condition, the settlement curves with the different consolidation settlements are shown in Figure 4. Due to the difference in the stiffness between the pile and the subsoil, the settlement above the pile and the subsoil is different under the embankment load. The settlement above 
TABLE 1: Experiment series.

\begin{tabular}{lccc}
\hline Pile diameter $(\mathrm{cm})$ & Reinforcement condition & Geogrid position & Consolidated settlement, $S_{\mathrm{c}}(\mathrm{mm})$ \\
\hline 25 & No geogrid layer & $/$ & 50 \\
25 & One-layer geogrid & $5 \mathrm{~cm}$ filling height & 50 \\
25 & Two-layer geogrids & $5 \mathrm{~cm}$ and $25 \mathrm{~cm}$ filling height & 50 \\
\hline
\end{tabular}

TABLE 2: Physical performance indexes of the triaxial geogrid.

\begin{tabular}{lcc}
\hline \multicolumn{2}{c}{ Parameters } & Value \\
\hline \multirow{2}{*}{ Rib length $(\mathrm{mm})$} & Landscape orientation & 40 \\
& Diagonal direction & 40 \\
Rib thickness $(\mathrm{mm})$ & Longitudinal direction & 1.5 \\
& Diagonal direction & 1.7 \\
Rib width $(\mathrm{mm})$ & Longitudinal direction & 1.3 \\
Node thickness $(\mathrm{mm})$ & Landscape orientation & 1.1 \\
Rib cross-sectional shape & 2.1 \\
Mass area ratio $\left(\mathrm{kg} / \mathrm{m}^{2}\right)$ & Rectangle \\
Node efficiency $(\%)$ & 0.21 \\
Density $\left(\mathrm{kg} / \mathrm{m}^{3}\right)$ & 100 \\
Tensile stiffness $(\mathrm{kN} / \mathrm{m})$ & 972 \\
Tensile strength $(\mathrm{kN} / \mathrm{m})$ & 421 \\
\hline
\end{tabular}

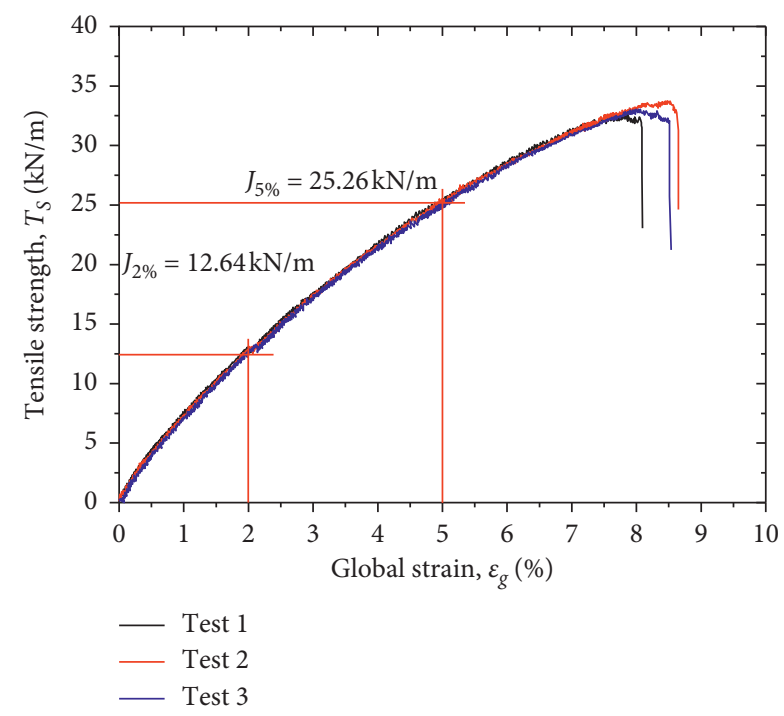

Figure 3: Single-rib tensile tests for the geogrid.

the subsoil is larger than the settlement above the piles. In order to reduce the differential settlement, a part of embankment load above the subsoil is transferred to the pile by the frictional shear action. The phenomenon that a part of embankment load above the subsoil is transferred to the pile is called soil arching effect. Obviously, with the increase of the consolidation settlement, the soil arching effect becomes increasingly obvious. With the increase of filling height, the settlement and differential settlement decrease significantly. When the consolidation settlement of subsoil is $50 \mathrm{~mm}$, the settlement at the filling height of $5 \mathrm{~cm}$ and $35 \mathrm{~cm}$ above the subsoil are $0.16 \mathrm{~cm}$ and 0.07 , respectively.

At the filling height of $5 \mathrm{~cm}$, the center point of the pile and the subsoil are denoted as points A and B, respectively, as shown in Figure 2. The differential settlement between the point $\mathrm{A}$ and the point $\mathrm{B}$ is recorded as $\Delta s$. The settlement curve of the section where the point $\mathrm{A}$ is located is shown in Figure 5, and the curve of the differential settlement $\Delta s$ versus filling height is shown in Figure 6. With the increase of filling height, the settlement of the section where the point A is located and $\Delta s$ decrease. With the increase of the consolidation settlement, the settlement of the section where point $\mathrm{A}$ is located and $\Delta s$ gradually increase. It shows that the consolidation settlement has a great influence on the settlement and differential settlement of filling.

In the consolidation settlement of the $30 \mathrm{~mm}$ condition, the settlement of the section where point $\mathrm{A}$ is located and $\Delta s$ with different reinforced conditions shows a nonlinear distribution with the change of filling height, as shown in Figures 7 and 8 . With the increase of filling height, the settlement of the section where point $\mathrm{A}$ is located and $\Delta s$ gradually decrease. For the same filling height, the settlement of the section where point $\mathrm{A}$ is located and $\Delta s$ in the reinforced condition is greater than that of the one-layer geogrid-reinforced condition, while the settlement of the section where point $\mathrm{A}$ is located and $\Delta s$ of the one-layer geogrid-reinforced condition is greater than that of the twolayer geogrid-reinforced condition. It indicates that whether or not the geogrid and the number of reinforcement layers have a significant effect on the long-term performance of the pile-supported embankment. Under the embankment load, the differential settlement between the pile and the subsoil causes tensile deformation of the geogrid. The tensile deformation causes the geogrid to produce a lifting force on the embankment load above the subsoil and transfers a part of embankment load above the pile. Thus, with the increasing layers of the geogrid, the differential settlement decreases gradually.

\section{Numerical Model and Verification}

3.1. Numerical Model. According to the model tests, the finite element software MIDAS is constructed in the numerical model. The calculation model is a plane model with taking one internode length and the pile length on both sides is half of the actual pile length. The pile diameter and the pile net spacing are $25 \mathrm{~cm}$. The length of the numerical model is $50 \mathrm{~cm}$, and the height is also $100 \mathrm{~cm}$, as shown in Figure 9 . The material parameters are selected according to laboratory tests. In order to simulate the mutual slip between the pile and the subsoil, an interface element is established between them. As shown in Table 3, in the numerical model, modulus of elasticity (calculated by the equivalent stiffness method), density, and Poisson ratio of the pile are $400 \mathrm{MPa}, 4800 \mathrm{~kg} /$ $\mathrm{m}^{3}$, and 0.3 , respectively, and those parameters of the geogrid are $850 \mathrm{MPa}, 972 \mathrm{~kg} / \mathrm{m}^{3}$, and 0.3 , respectively. The 


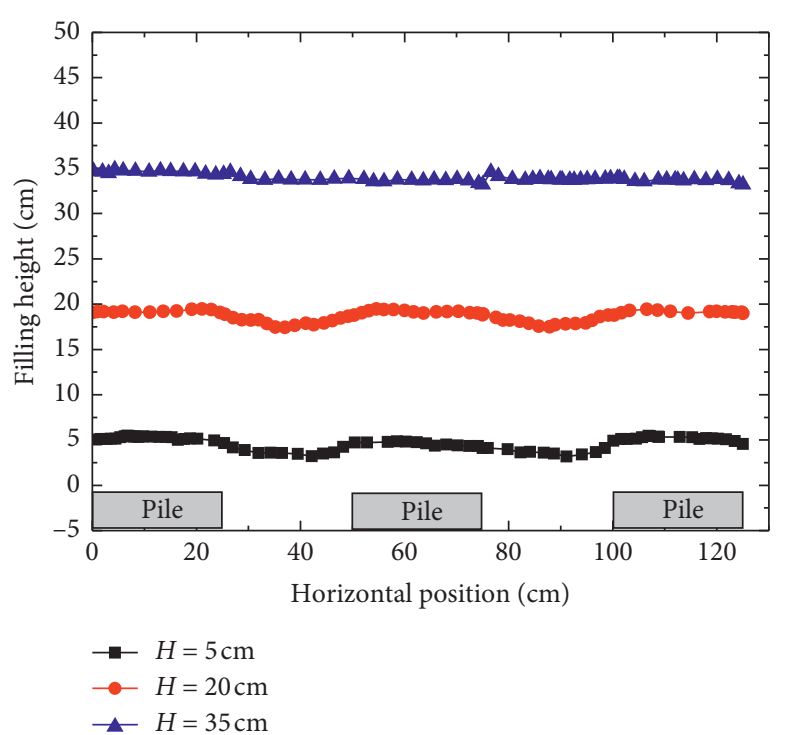

(a)

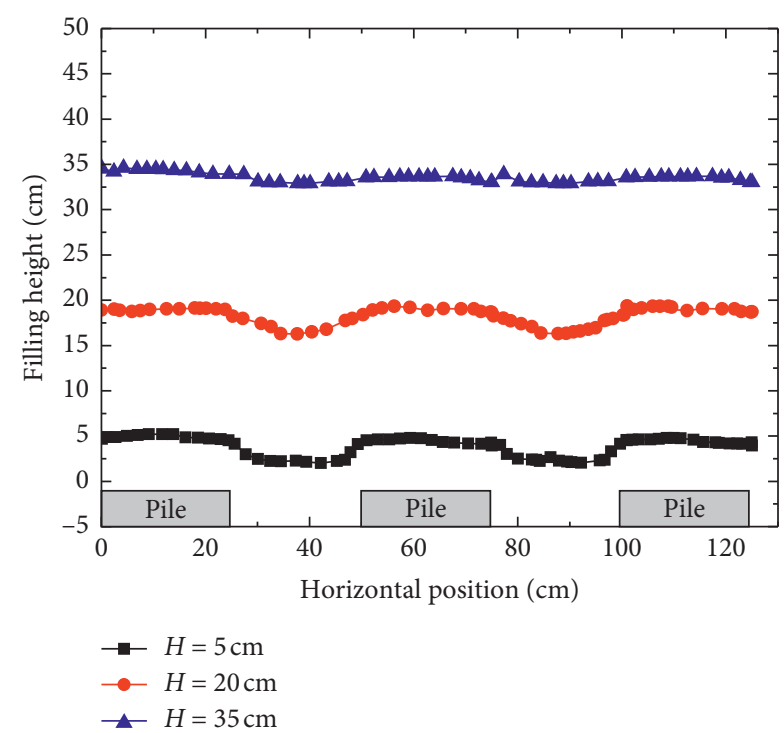

(b)

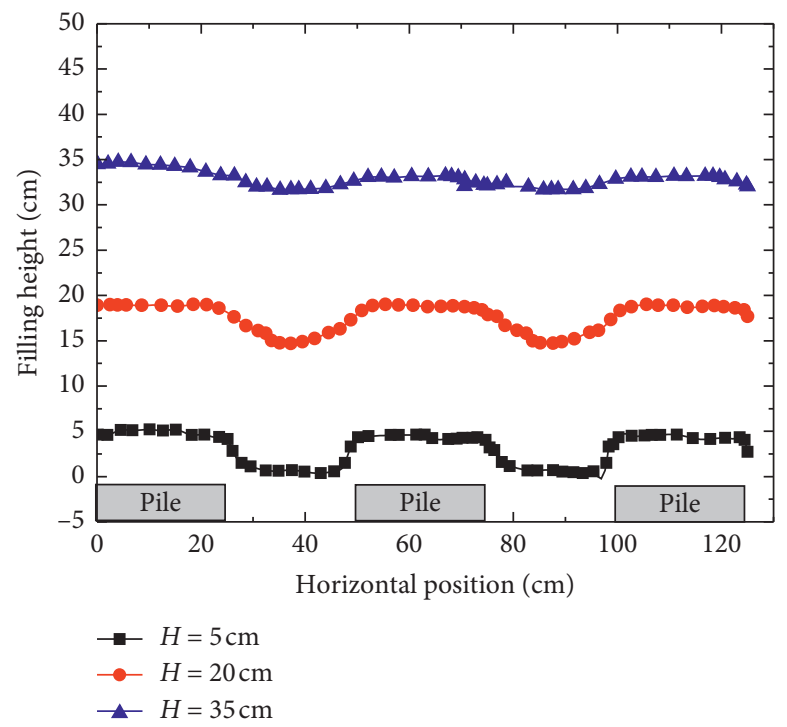

(c)

Figure 4: Settlement curves at different filling heights. (a) Consolidation settlement of $10 \mathrm{~mm}$. (b) Consolidation settlement of $30 \mathrm{~mm}$. (c) Consolidation settlement of $50 \mathrm{~mm}$.

Mohr-Coulomb constitutive model is adopted for the sand in the numerical model. And, the modulus of elasticity, density, Poisson ratio, and internal frictional angle of sand are $20 \mathrm{MPa}, 1620 \mathrm{~kg} / \mathrm{m}^{3}, 0.3$, and $27^{\circ}$, respectively.

The surface of the numerical model is a free boundary, and the two sides are normal displacement constraint boundary conditions. The constraints of the model bottom are divided into two groups according to the test conditions. The first group is fixed boundary conditions, which have been constraining the model throughout the whole test process. The other group is released in accordance with the sinking of subsoil at the model bottom.

Firstly, the initial in situ stress is balanced, and the displacement is cleared to zero. Then, the settlement is simulated by releasing the constraint on the bottom of the subsoil and applying vertical downward displacement to the corresponding nodes. The software construction phase analysis is adopted, and the displacement increment is applied step by step from zero to $50 \mathrm{~mm}$.

3.2. Model Validation. To ensure a reasonable representation, the model calibration is conducted according to the model test. Figure 10 shows the curves of the differential settlement $\Delta s$ versus filling height obtained from both the model test and numerical model in the one-layer geogridreinforced condition. It indicates that the numerical simulation results are in good agreement with the model test results. Therefore, the numerical model is validated and can be used for the investigation of the GRPS embankment. 


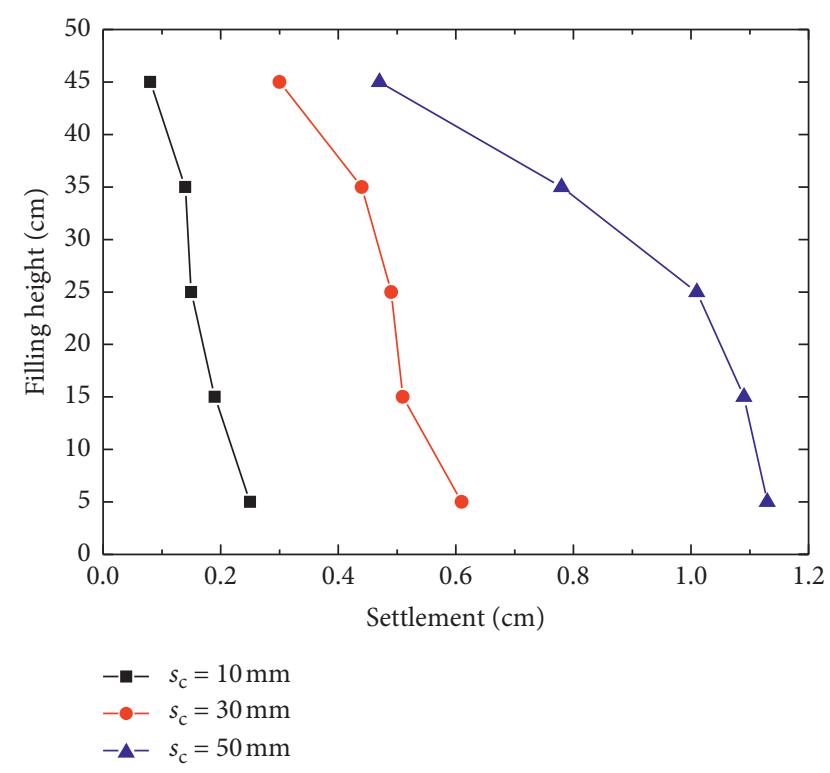

FIGURE 5: Variation of the settlement with filling height under different consolidation settlement conditions.

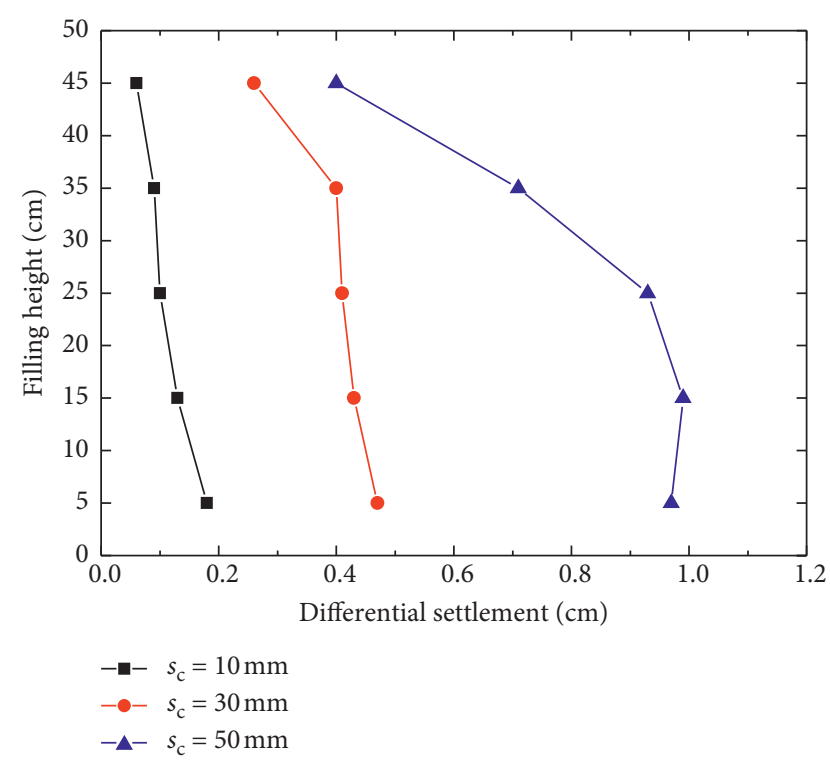

FIgURE 6: Variation of the differential settlement with filling height under different consolidation settlement conditions.

\section{Influence Factors}

In order to study the long-term performance of the GRPS embankment, the parameters of pile net spacing, pile modulus, and filling modulus are analyzed. At the same time, the comparative analysis is carried out for each condition without the geogrid and one layer of the geogrid arranged on filling height of $5 \mathrm{~cm}$. The details of influence factors are shown in Table 4.

4.1. Influence of Pile Net Spacing. Figure 11 shows the settlement of the central line of filling in the different pile-net

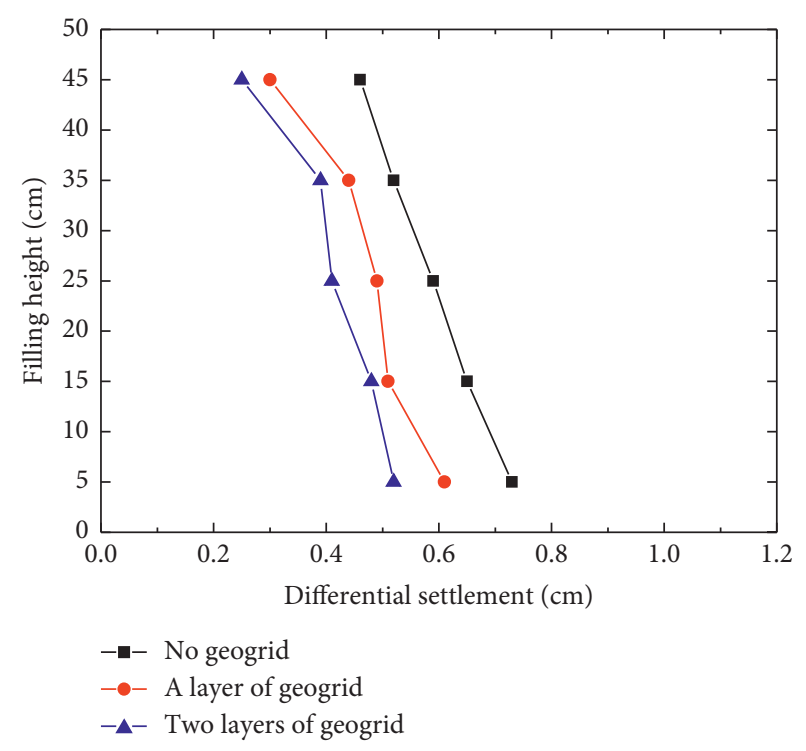

FIGURE 7: Variation of the settlement with filling height under different reinforced conditions.

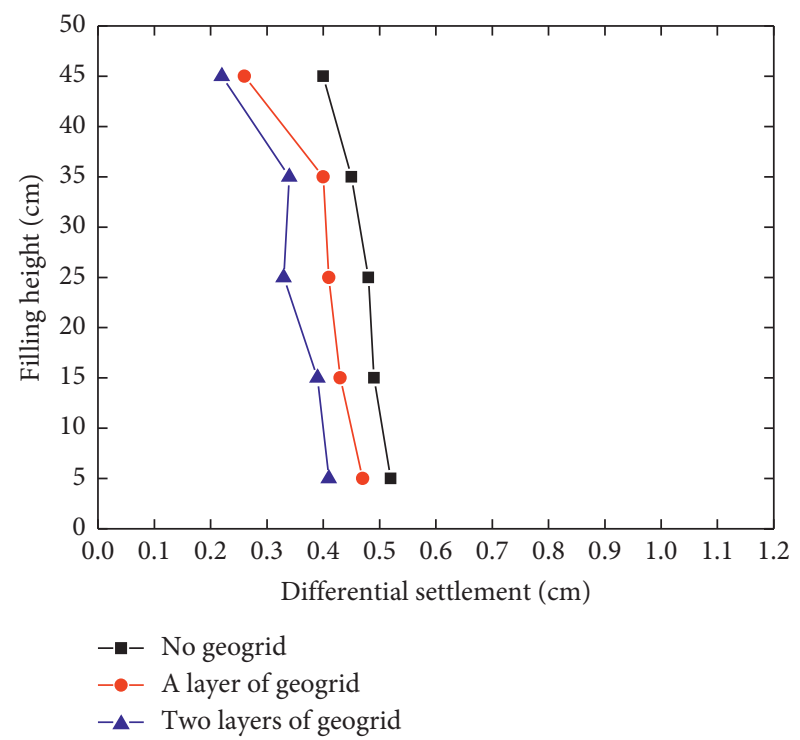

FIGURE 8: Variation of the differential settlement with filling height under different reinforced conditions.

spacing conditions when the consolidation settlement is $30 \mathrm{~mm}$. The pile net spacing in the unreinforced and onelayer geogrid-reinforced conditions is recorded as $S$ and $S_{\mathrm{g}}$, respectively. It indicates that the settlement of the central line of filling decreases with the increase of the filling height in the different reinforced conditions. The settlement in the reinforced condition is smaller than that in the unreinforced condition. In the unreinforced condition, the settlement is changed greatly below the filling height of $25 \mathrm{~cm}$, but changed smaller above the filling height of $25 \mathrm{~cm}$. However, the difference between the settlement above and below the filling height of $25 \mathrm{~cm}$ is not very significant. It indicates that the group stability of filling is improved by the geogrid. As 


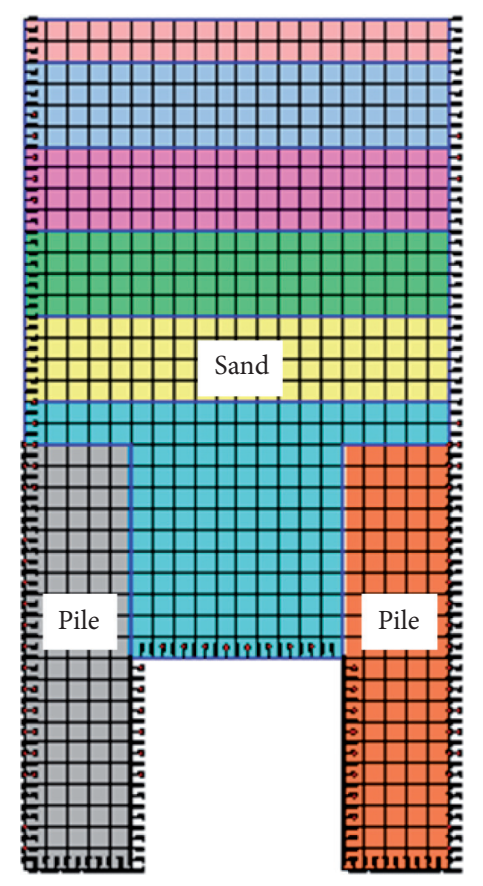

Figure 9: Meshing of the numerical model.

TABle 3: Mechanical parameters for the numerical model.

\begin{tabular}{lccc}
\hline Parameters & Pile & Sand & Geogrid \\
\hline Modulus of elasticity $(\mathrm{MPa})$ & 400 & 20 & 850 \\
Density $\left(\mathrm{kg} / \mathrm{m}^{3}\right)$ & 4800 & 1620 & 972 \\
Poisson ratio & 0.3 & 0.3 & 0.3 \\
Internal frictional angle $\left({ }^{\circ}\right)$ & $/$ & 27 & $/$ \\
\hline
\end{tabular}

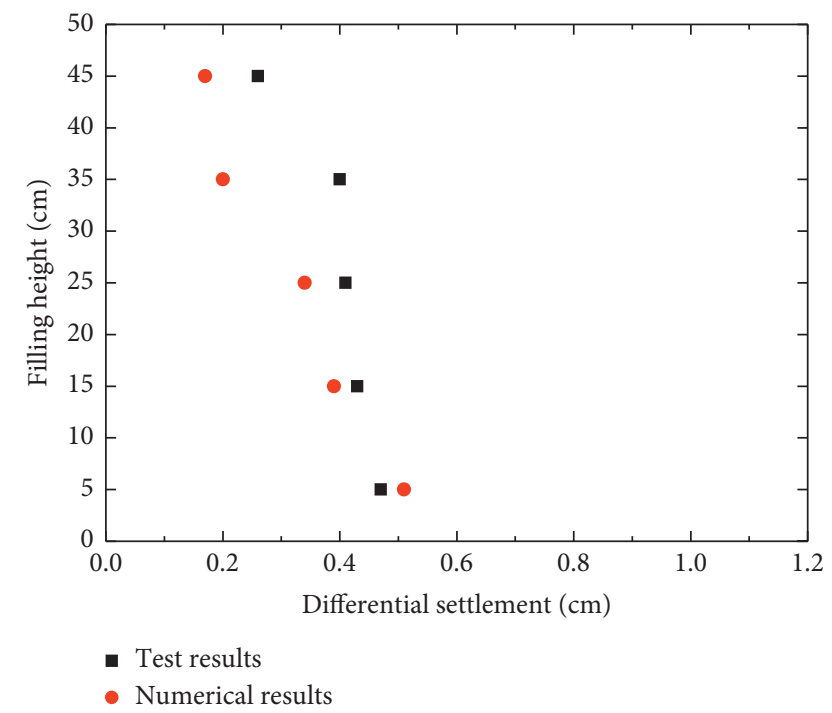

Figure 10: Comparison of differential settlement between the model test and numerical model.

the net pile spacing increases, the settlement of the central line increases, and the degree of increase is almost the same.

The comparison between the unreinforced and one-layer geogrid-reinforced conditions with the different pile net spacing is shown in Figure 12, which illustrates that, with the increase of pile net spacing, the settlements in those conditions increase in various degrees, and the effect of the geogrid is more significant.

The settlement of the central line of filling in Figure 13 is analyzed in the different consolidation settlements' conditions. The bar chart represents the condition of pile net spacing $S=15 \mathrm{~cm}$, the broken line chart represents the condition of pile net spacing $S=25 \mathrm{~cm}$, and the scatter chart represents the condition of pile net spacing $S=35 \mathrm{~cm}$. $H-5$ represents the condition of filling height of $5 \mathrm{~cm}$ and without the geogrid, while $H G-5$ represents the condition of filling height of $5 \mathrm{~cm}$ and with the one-layer geogrid. It can be seen that the consolidation settlement has a great influence on the settlement of filling, which is reflected in the height difference of three columns and the large vertical interval of three curves in Figure 13.

4.2. Influence of Pile Modulus. Figure 14 shows the settlement of the central line of filling considering different pile modulus when the consolidation settlement is $30 \mathrm{~mm}$. The pile modulus in the unreinforced and one-layer geogridreinforced conditions is recorded as $E_{\mathrm{p}}$ and $E_{\mathrm{pg}}$, respectively. It indicates that the settlement of the central line decreases with the increase of the filling height. Figure 14(a) shows that the settlement of the central line is nearly $1.5 \mathrm{~cm}$ when filling height is $5 \mathrm{~cm}$, while Figure 14(b) reflects that the settlement at the same position is nearly $1.25 \mathrm{~cm}$. The reason is that geogrid reinforcement can reduce the settlement of filling.

The comparison between the unreinforced and one-layer geogrid-reinforced conditions with the different pile modulus is shown in Figure 15, which illustrates that, with the 
TABLE 4: Details of influence factors.

\begin{tabular}{|c|c|c|c|c|c|}
\hline Pile net spacing, $S(\mathrm{~cm})$ & 15 & 25 & 35 & I & I \\
\hline Pile modulus, Ep (MPa) & 100 & 200 & 400 & 800 & 1200 \\
\hline Fill modulus, Ef (MPa) & 20 & 40 & 60 & / & / \\
\hline
\end{tabular}

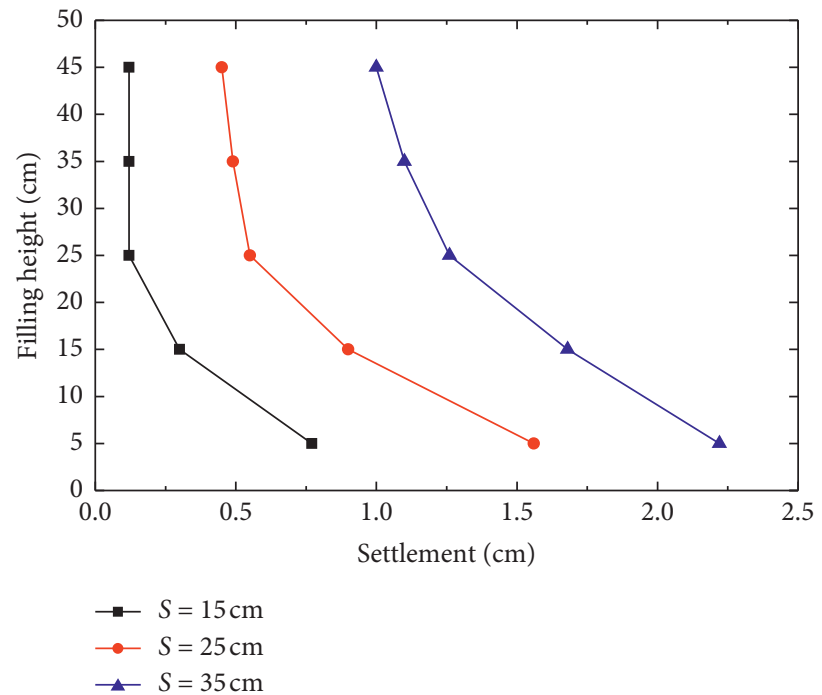

(a)

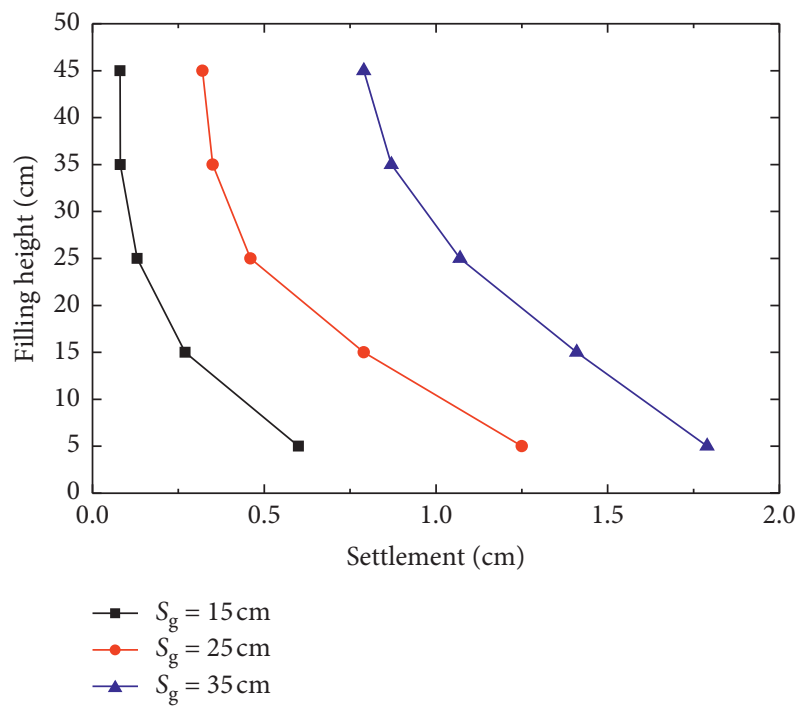

(b)

FIGURE 11: Variation of the settlement with filling height under different pile net spacing conditions. (a) Unreinforced condition. (b) Onelayer geogrid-reinforced condition.

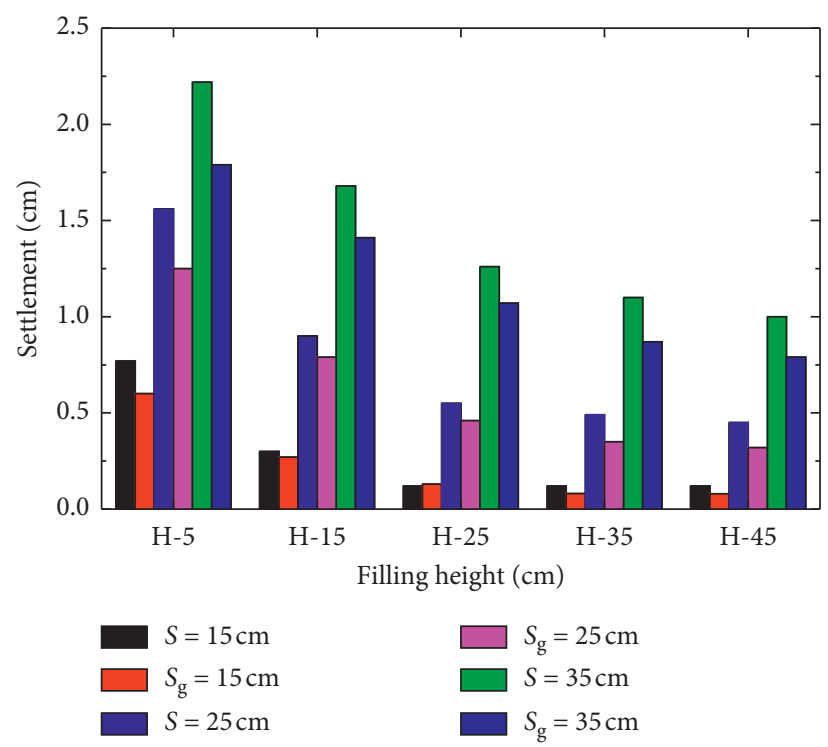

FIGURE 12: Comparison of the settlement between unreinforced and reinforced conditions.

increase of pile modulus, the settlement of filling increases. Similarly, the reinforcement has a certain inhibitory effect to reduce the settlement of filling.

The settlement of the central line of filling in Figure 16 is analyzed under the different consolidation settlements' conditions. The bar chart represents the condition of pile modulus $E_{\mathrm{p}}=100 \mathrm{MPa}$, the broken line chart represents the condition pile modulus $E_{\mathrm{p}}=400 \mathrm{MPa}$, and the scatter chart represents the condition of pile modulus $E_{\mathrm{p}}=1200 \mathrm{MPa}$. It indicates that the change of pile modulus has little effect on the settlement of filling. The small stress on the pile induced by relatively small-scale model test results show that the 


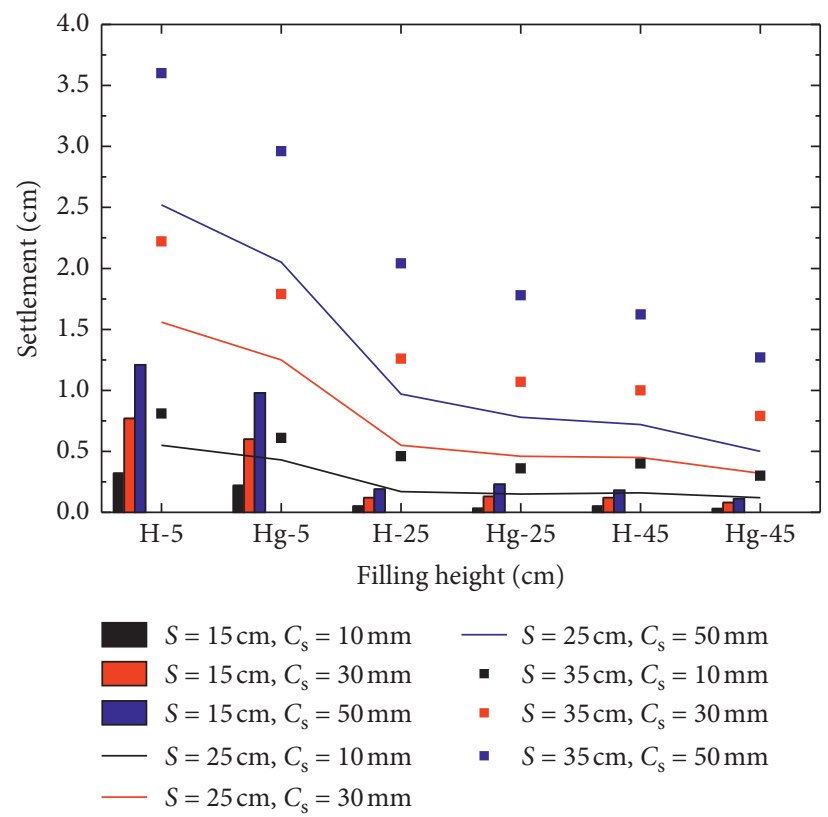

FIGURE 13: Variation of the settlement with different consolidation settlements.

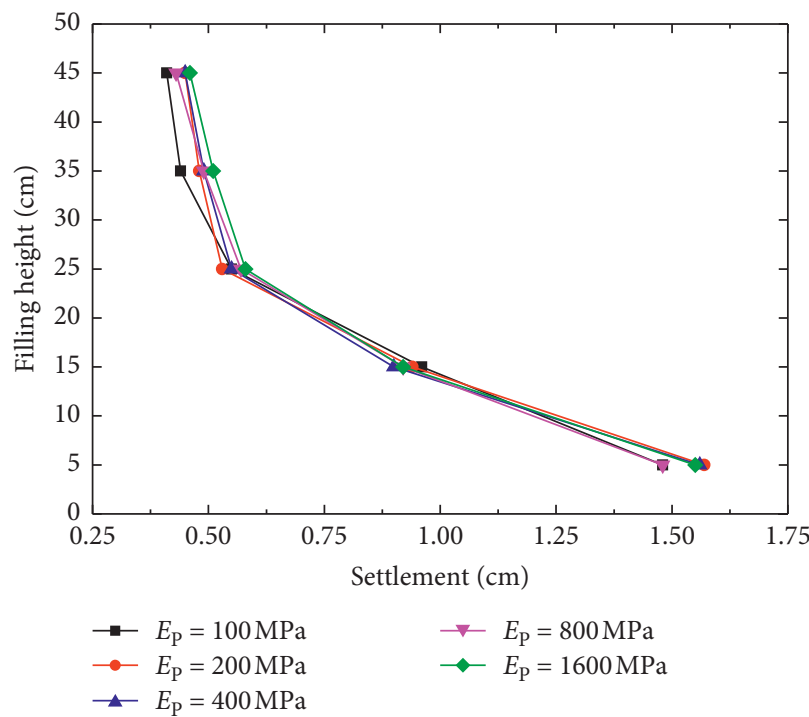

(a)

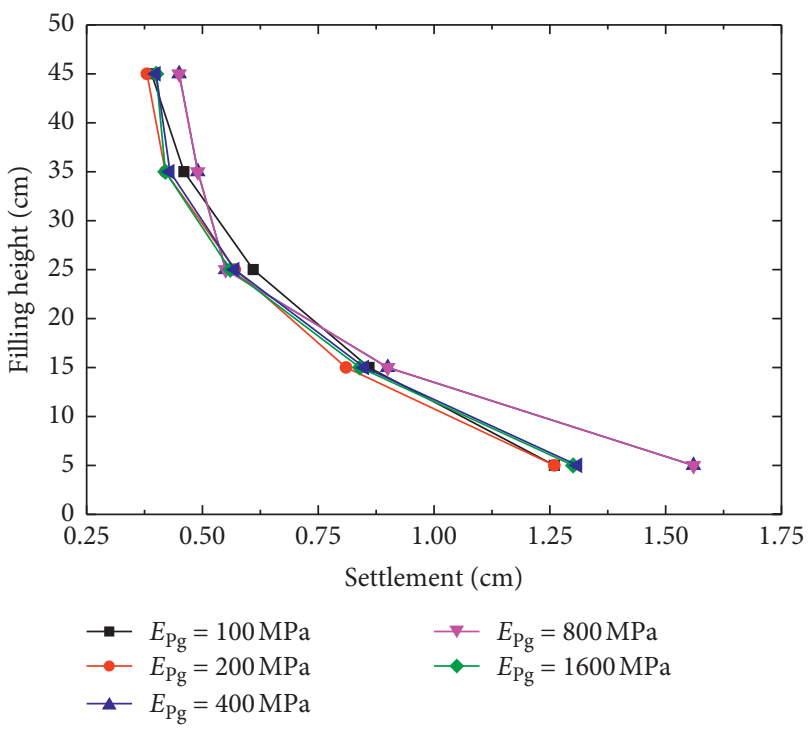

(b)

Figure 14: Variation of the settlement with filling height under different pile modulus conditions. (a) Unreinforced condition. (b) One-layer geogrid-reinforced condition.

influence pile modulus is not obvious. When the pile modulus is $400 \mathrm{MPa}$, the effect of the geogrid is the best. The settlement of the central line in the one-layer geogridreinforced condition is about $80 \%$ of that unreinforced condition averagely.

4.3. Influence of Filling Modulus. Figure 17 shows the settlement of the central line of filling in the different filling modulus conditions when the consolidation settlement is $30 \mathrm{~mm}$. The filling modulus in the unreinforced and onelayer geogrid-reinforced conditions is recorded as $E_{\mathrm{f}}$ and $E_{\mathrm{fg}}$, respectively. It indicates that the settlement of the central line decreases with the increase of the filling height in the different reinforced conditions. Filling modulus has obvious effect on the settlement of the pile-supported embankment. Figure 17(a) shows that the settlement of filling decreases gradually with the increase of the filling modulus. When the 


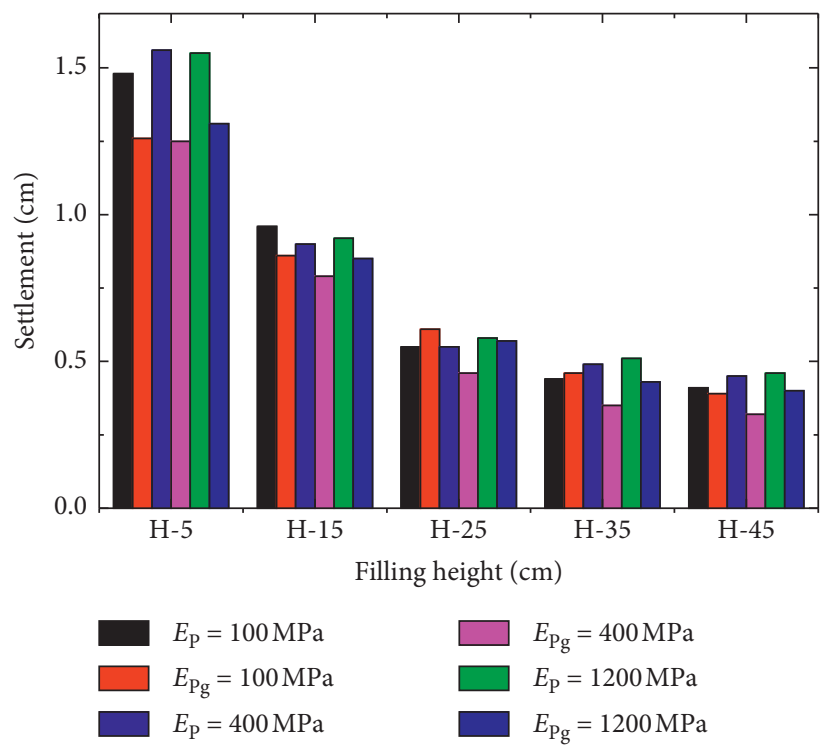

FIgURE 15: Comparison of the settlement between unreinforced and reinforced conditions.

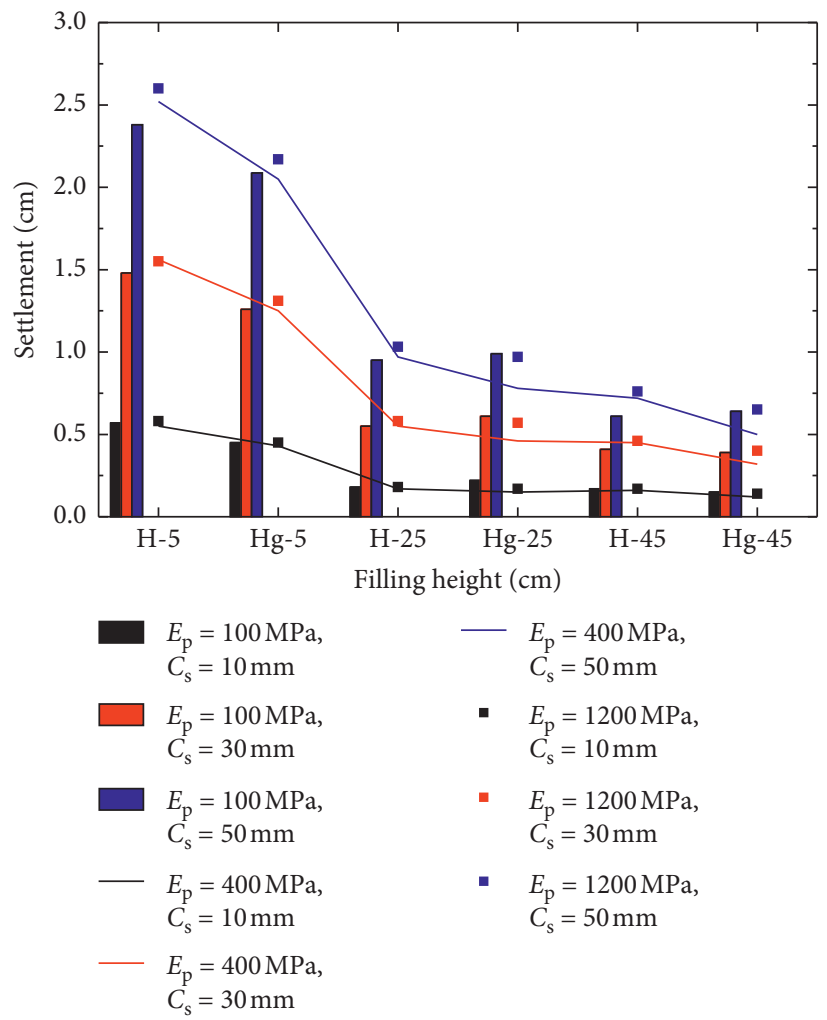

FIGURE 16: Variation of the settlement with different consolidation settlements.

filling height is $5 \mathrm{~cm}$, the effect is most obvious. As shown in Figure 17(b), the effect of filling modulus on the settlement of filling in the reinforced condition is greater than that in the unreinforced condition.

The comparison between the unreinforced and one-layer geogrid-reinforced conditions with the different filling modulus is shown in Figure 18, which illustrates that, with the increase of filling modulus, the settlement of filling in the pilesupported embankment decreases. Similarly, the reinforcement has a certain inhibitory effect on the settlement of filling.

The settlement of the central line of filling in Figure 19 is analyzed under the different consolidation settlement 


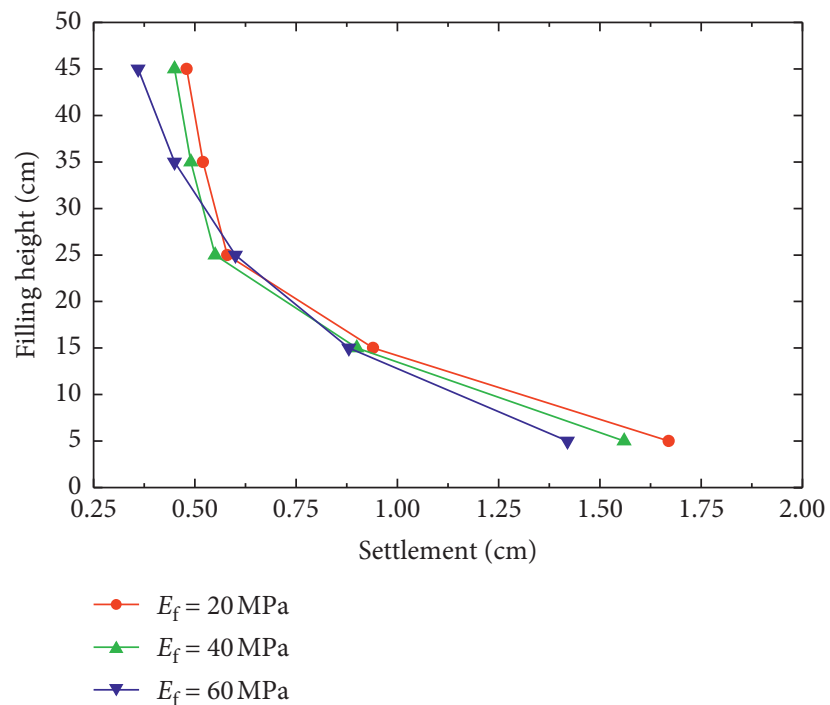

(a)

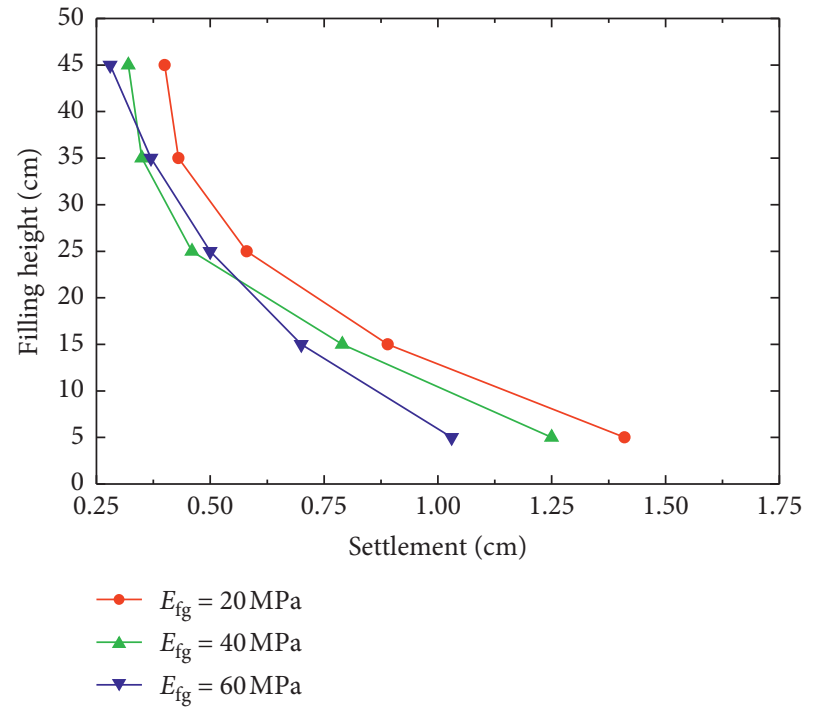

(b)

Figure 17: Variation of the settlement with filling height under different filling modulus conditions. (a) Unreinforced condition. (b) Onelayer geogrid-reinforced condition.

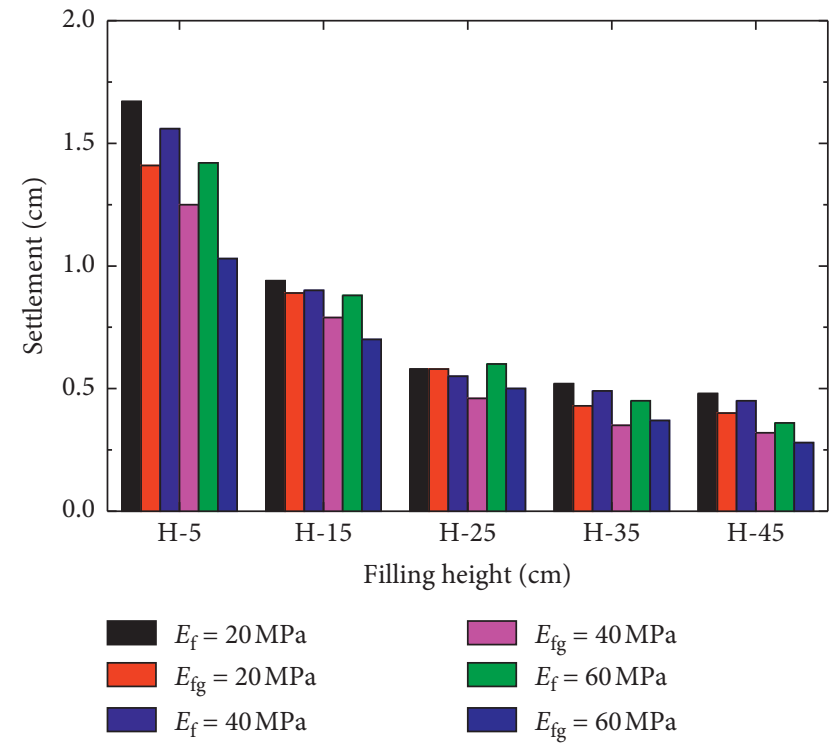

FIgURE 18: Comparison of the settlement between unreinforced and reinforced conditions.

conditions. The bar chart represents the condition of filling modulus $E_{\mathrm{f}}=20 \mathrm{MPa}$, the broken line chart represents the condition filling modulus $E_{\mathrm{f}}=40 \mathrm{MPa}$, and the scatter chart represents the condition of filling modulus $E_{\mathrm{f}}=60 \mathrm{MPa}$. It indicates that, as the filling modulus increases, the settlement of filling in the pile-supported embankment decreases.

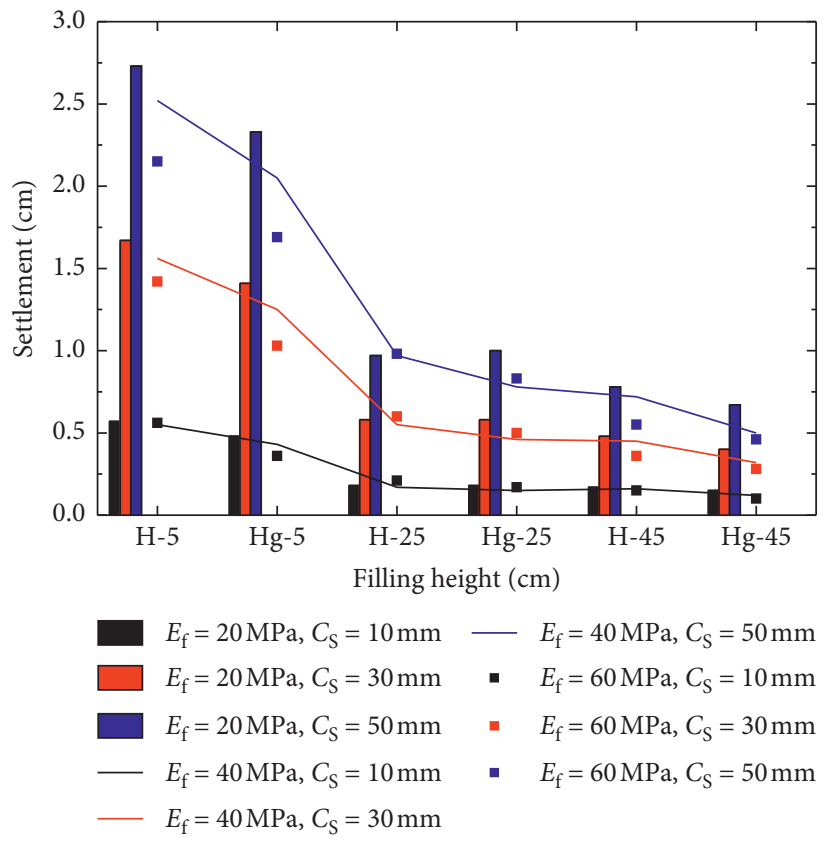

FIGURE 19: Variation of the settlement with different consolidation settlements.

\section{Conclusions}

In this study, a series of model tests are carried out to evaluate the long-term performance of GRPS embankments using a specially designed model box. Then, the numerical model is established by using the finite element software 
MIDAS, and the accuracy and effectiveness of the calculation model are verified by the model test results. Finally, a parametric study is conducted to investigate the influences of pile net spacing, pile modulus, and filling modulus. Based on the analysis and discussion of the results, the following conclusions can be drawn:

(1) The consolidation settlement has a great influence on the settlement and differential settlement of filling, and consolidation settlement must be considered when the GRPS embankment is applied at bridge approach.

(2) The accuracy and effectiveness of the finite element numerical model established have been well verified.

(3) The settlement and differential settlement of filling increase with the increase of the consolidation settlement and decrease with the increase of filling height. Furthermore, the settlement tends to be constant with the filling height increase. In addition, the settlement of filling can be reduced to some extent by the geogrid.

(4) The pile net spacing has the most significant effect on the settlement of filling, the pile modulus has the least effect, and the filling modulus is between the two. With the increase of pile net spacing, the settlement of filling increases, but the degree of increasing is gradually decreased. With the increase of filling modulus, the settlement of filling decreases. However, the pile modulus has a limit effect on the settlement of filling.

\section{Data Availability}

The data used to support the findings of this study are included within this article.

\section{Conflicts of Interest}

The authors declare that there are no conflicts of interest regarding the publication of this paper.

\section{Acknowledgments}

The authors are thankful for the financial support received from the National Key R\&D Program of China (Grant no. 2018YFB1600100) and National Natural Science Foundation of China (NSFC) (Grant no. 51608316).

\section{References}

[1] Y. W. Zheng and P. J. Fox, "Numerical investigation of geosynthetic-reinforced soil bridge abutments under static loading," Journal of Geotechnical and Geoenvironmental Engineering, vol. 142, no. 5, 2016.

[2] Q. Chen and M. Abu-Farsakh, "Mitigating the bridge end bump problem: a case study of a new approach slab system with geosynthetic reinforced soil foundation," Geotextiles and Geomembranes, vol. 44, no. 1, pp. 39-50, 2016.

[3] K. Liu, Q. Su, P. Ni, C. Zhou, W. Zhao, and F. Yue, "Evaluation on the dynamic performance of bridge approach backfilled with fibre reinforced lightweight concrete under high-speed train loading," Computers and Geotechnics, vol. 104, pp. 4253, 2018.

[4] K. Q. Lin and I. H. Wong, "Use of deep cement mixing to reduce settlements at bridge approaches," Journal of Geotechnical and Geoenvironmental Engineering, vol. 125, no. 4, pp. 309-320, 1999.

[5] S. Feng, R. Xu, J. Yu et al., "Field monitoring of geogridreinforced and pile-supported embankment at bridge approach," International Journal of Geosynthetics and Ground Engineering, vol. 7, no. 2, 2021.

[6] J. Zhang, J. Zheng, D. Zhao, and S. Chen, "Field study on performance of new technique of geosynthetic-reinforced and pile-supported embankment at bridge approach," Science China Technological Sciences, vol. 59, no. 1, pp. 162-174, 2016.

[7] T. Eskisar, J. Otani, and J. Hironaka, "Visualization of soil arching on reinforced embankment with rigid pile foundation using X-ray CT," Geotextiles and Geomembranes, vol. 32, pp. 44-52, 2012.

[8] J. Han, A. Bhandari, and F. Wang, "DEM analysis of stresses and deformations of geogrid-reinforced embankments over piles," International Journal of Geomechanics, vol. 12, no. 4, pp. 440-350, 2012.

[9] H. Xing, Z. Zhang, H. Liu, and H. Wei, "Large-scale tests of pile-supported earth platform with and without geogrid," Geotextiles and Geomembranes, vol. 42, no. 6, pp. 586-598, 2014.

[10] K. Terzaghi, "Stress distribution in dry and in saturated sand above a yielding trap-door," in Proceeding of 1st International Conference: Soil Mechanics, pp. 307-311, Harvard University, Cambridge, UK, June 1936.

[11] R. P. Chen, Y. M. Chen, J. Han, and Z. Z. Xu, "A theoretical solution for pile-supported embankments on soft soils under one-dimensional compression," Canadian Geotechnical Journal, vol. 45, no. 5, pp. 611-623, 2008.

[12] J. Yu, Y. T. Zhou, S. Bao et al., "Pile-soil stress eatio of deformable pile-supported geosynthetics-reinforced embankments," Chinese Journal of Geotechnical Engineering, vol. 33, no. 5, pp. 705-713, 2011.

[13] W. Lu and L. Miao, "A simplified 2-D evaluation method of the arching effect for geosynthetic-reinforced and pile-supported embankments," Computers and Geotechnics, vol. 65, pp. 97-103, 2015.

[14] I. O. Young and C. S. Eun, "Reinforcemetn and arching effect of geogrid-reinforced and pile-supported embankment on marine soft ground," Marine Georesources \& Geotechnology, vol. 25, no. 2, pp. 97-118, 2007.

[15] Y. M. Chen, W. P. Cao, and R. P. Chen, "An experimental investigation of soil arching within basal reinforced and unreinforced piled embankments," Geotextiles and Geomembranes, vol. 26, no. 2, pp. 164-174, 2008.

[16] S. J. M. Van Eekelen, A. Bezuijen, H. J. Lodder, and A. F. van Tol, "Model experiments on piled embankments. Part I," Geotextiles and Geomembranes, vol. 32, pp. 69-81, 2012.

[17] O. Jenck, D. Dias, and R. Kastner, "Discrete element modelling of a granular platform supported by piles in soft soil validation on a small scale model test and comparison to a numerical analysis in a continuum," Computers and Geotechnics, vol. 36, no. 6, pp. 917-927, 2009.

[18] B. Le Hello and P. Villard, "Embankments reinforced by piles and geosynthetics-numerical and experimental studies dealing with the transfer of load on the soil embankment," Engineering Geology, vol. 106, no. 1-2, pp. 178-191, 2009. 